\title{
Protein Biomarkers for the Early Detection of Breast Cancer
}

\author{
David E. Misek ${ }^{1,2}$ and Evelyn H. Kim ${ }^{1}$ \\ ${ }^{1}$ Department of Surgery, University of Michigan Medical School, Ann Arbor, MI 48109-5656, USA \\ ${ }^{2}$ The Comprehensive Cancer Center, University of Michigan Medical School, Ann Arbor, MI 48109-5656, USA
}

Correspondence should be addressed to David E. Misek, dmisek@umich.edu

Received 24 May 2011; Accepted 23 June 2011

Academic Editor: Tadashi Kondo

Copyright (C) 2011 D. E. Misek and E. H. Kim. This is an open access article distributed under the Creative Commons Attribution License, which permits unrestricted use, distribution, and reproduction in any medium, provided the original work is properly cited.

\begin{abstract}
Advances in breast cancer control will be greatly aided by early detection so as to diagnose and treat breast cancer in its preinvasive state prior to metastasis. For breast cancer, the second leading cause of cancer-related death among women in the United States, early detection does allow for increased treatment options, including surgical resection, with a corresponding better patient response. Unfortunately, however, many patients' tumors are diagnosed following metastasis, thus making it more difficult to successfully treat the malignancy. There are, at present, no existing validated plasma/serum biomarkers for breast cancer. Only a few biomarkers (such as HER-2/neu, estrogen receptor, and progesterone receptor) have utility for diagnosis and prognosis. Thus, there is a great need for new biomarkers for breast cancer. This paper will focus on the identification of new serum protein biomarkers with utility for the early detection of breast cancer.
\end{abstract}

\section{Introduction}

Advances in breast cancer control will be greatly aided by early detection, thereby facilitating diagnosis and treatment of breast cancer in its preinvasive state prior to metastasis. Breast cancer is the most frequently occurring malignancy and the second leading cause of cancer-related death for women in the United States [1]. The most efficacious screening modality utilized in the clinic is mammography though lesions less than $0.5 \mathrm{~cm}$ in size remain undetectable by present technology. Importantly, however, even though a breast lesion may be detected, given the low sensitivity/specificity of mammography, approximately 4 -fold more women (than those with breast malignancies) have resultant biopsies. Five-year survival of women with breast cancer is highly correlated with tumor stage, with tumor detection at very early stages (stages 0 and I) having an approximate 98\% 5 -year survival. Five-year survival for stage II tumors is approximately $85 \%$, stage III approximately $60 \%$, and stage IV approximately $20 \%$. Overall, breast cancer has an approximate $80 \%$ 5-year survival, with 207,090 new cases and 39,840 deaths expected in women in the United States in 2010 [1].

Early detection of breast cancer does allow for increased treatment options, including surgical resection, with a cor- responding better patient response. Surgical resection may involve lumpectomy or mastectomy with removal of some of the axillary lymph nodes. Following early detection, radiation therapy, chemotherapy (before or after surgery), and hormone therapy (tamoxifen [2] and aromatase inhibitors [3-5]) also have utility for therapeutic intervention. Targeted biologic therapy with trastuzumab (Herceptin) [6] or lapatinib (Tykerb) $[7,8]$ also has utility to treat HER2/neu-positive breast tumors. Unfortunately, however, in the absence of good serum/plasma biomarkers many breast cancer patients are diagnosed too late in the disease process (i.e., after the tumors metastasize) for surgical resection to be an effective option. Thus, these patients are typically offered various therapeutic treatment modalities dependent upon tumor subtype $\left(\mathrm{ER}^{+}\right.$or $\mathrm{ER}^{-}$; HER2 ${ }^{+}$or $\left.\mathrm{HER} 2^{-}\right)$. The available treatment modalities may include hormonal (antiestrogen), taxane (docetaxel or paclitaxel) or nontaxane chemotherapy. In general, women with metastatic breast cancer are provided one therapeutic modality until treatment failure and are then switched to another therapeutic modality.

The origin of most breast cancer cases is not known. However, many risk factors have been identified, including female gender, increasing patient age, family history of breast 
cancer at an early age, early menarche, late menopause, older maternal age at first live childbirth, prolonged hormone replacement therapy, exposure to therapeutic chest irradiation, benign proliferative breast disease, and genetic mutations in genes such as BRCA1/2 [9]. The overwhelming majority of breast masses detected by palpation and/or by mammography are epithelial lesions, which include benign fibrocystic change, hyperplasia, carcinoma in situ, and infiltrating mammary carcinoma. Although several histologic types and subtypes of mammary carcinomas exist, $>95 \%$ are either ductal or lobular carcinomas [10], with the majority (75\%-80\%) of mammary carcinomas being ductal carcinomas $[11,12]$.

A number of genetic alterations have been identified in breast tumors. The most frequent genomic aberrations identified are gains along chromosomes 1q, 8q, 17q, 20q, and $11 \mathrm{q}$ and losses along 8p, 13q, 16q, 18q, and 11q [13-18]. Interestingly, many of these chromosomal segments harbor known proto-oncogenes and/or tumor suppressor genes such as BRCA1, BRCA2, HER2-neu, C-MYC, and Cyclin D1. Low-grade (grade 1) infiltrating ductal carcinomas have relatively few numbers of chromosomal alterations with the highest frequency of aberrations occurring as losses on $16 \mathrm{q}$ and gains on 1q.

It is generally accepted that estrogen receptor-positive $\left(\mathrm{ER}^{+}\right)$and ER-negative $\left(\mathrm{ER}^{-}\right)$breast cancers are two different disease entities. $\mathrm{ER}^{-}$tumors tend to be of high grade, have more frequent p53 mutations, and have worse prognosis compared with $\mathrm{ER}^{+}$disease. Both $\mathrm{ER}^{+}$and $\mathrm{ER}^{-}$tumors can be either HER2 positive or negative. Low-grade tumors are typically ER positive, almost always HER2 nonamplified, and frequently overexpress cyclin D-1 [10]. In contrast, high-grade (grade 3 ) tumors tend to be ER negative, have frequent loss of p53 function, usually overexpress C-MYC and commonly overexpress HER2 $[13-15,19]$. In the highgrade tumors, loss of p53 function is usually due to $17 \mathrm{p} 13$ deletion, mutation or inactivation, while overexpression of HER2 is usually because of 17q12 amplification [20-28].

Although early detection of cancer has improved survival for a number of cancers, including breast cancer [29], colon cancer [30-32], prostate cancer [33, 34], and cervical cancer [35], existing serum biomarkers for breast cancer are not adequate for early detection. The possibility of early detection of breast cancer may be realized through both noninvasive (i.e., imaging technologies) and invasive means (patient serum profiling). To date, gains in the early detection of breast cancer have been largely made due to routine mammography and/or by palpation (either self-examination or by physician or nurse practitioner). Imaging technologies (mammography, digital mammography, and magnetic resonance imaging (MRI)) have been adopted clinically for mass screening purposes, but there is resistance for seeking such services on a yearly basis, given the relative complexity and high cost-to-benefit ratio of these imaging methodologies. As a result, there has been much interest in development and validation of serum-based biomarkers for the early detection, risk stratification, prediction, and disease prognosis of breast cancer. This paper will focus on recent developments in iden- tification of new serum protein biomarkers with potential utility for the early detection of breast cancer (Table 1).

\section{Autoantibodies and Breast Cancer}

The humoral immune response to cancer in humans has been well demonstrated by identification of autoantibodies to a number of different intracellular and surface antigens in patients with various tumor types [36-39]. A tumor-specific humoral immune response directed against oncoproteins $[40,41]$, mutated proteins such as p53 [42, 43], or other aberrantly expressed proteins have all been described. While it is currently unknown whether the occurrence of such antibodies is beneficial, knowledge of potential tumor antigens that may evoke tumor-specific immune responses may have utility in early cancer diagnosis, in establishing prognosis and in immunotherapy against the disease.

Several approaches are currently available for the identification of tumor antigens. In contrast to identification of tumor antigens based on analysis of recombinant proteins (which do not contain posttranslational modifications as found in tumors or tumor cell lines), it may be preferable to utilize a proteomics-based approach for the identification of tumor antigens. This may facilitate the identification of autoantibodies to naturally occurring proteins, such as in lysates prepared from tumors and tumor cell lines, and may uncover antigenicity associated with aberrant posttranslational modification of tumor cell proteins. Such a proteomics approach was implemented for the identification of breast tumor antigens that elicit a humoral response against proteins that are expressed in the SUM-44 breast cancer cell line. 2D PAGE was used to simultaneously separate individual cellular proteins from the SUM-44 cell line. The separated proteins were transferred onto PVDF membranes. Sera from breast cancer patients were screened individually for antibodies that reacted against the separated proteins by Western blot analysis. Proteins specifically reacting with sera from the breast cancer patients were identified by mass spectrometry. Le Naour and colleagues [36] have shown that a humoral response directed against RS/DJ-1 occurred in $13.3 \%$ of newly diagnosed breast cancer patients. None of the 25 healthy controls $(0 \%)$ or 46 patients $(0 \%)$ with hepatocellular carcinoma exhibited autoantibodies to RS/DJ-1. Only $2 / 54(3.7 \%)$ samples of sera from lung adenocarcinoma patients demonstrated autoantibodies to RS/DJ-1.

In breast cancer, besides RS/DJ-1 [36], autoimmunity has also been shown against a number of other cellular proteins. These proteins include p53 [44-47], heat shock protein 60 $[48,49]$, heat shock protein $90[50,51]$, and mucin-related antigens $[49,52-54]$. The presence of p53 autoantibodies have been observed in $15 \%$ of patients with breast cancer and were shown to be associated with a poor prognosis [44, 45, 47]. However, p53 autoantibodies have also been found in patients with other malignancies and inflammatory conditions $[42,43]$, thus the humoral response to p53 is not specific to breast cancer. A humoral response to the $90 \mathrm{kDa}$ heat shock protein has also been associated with poor survival in breast cancer [51]. In contrast, the presence of MUC1 
TABLE 1: Current promising biomarkers for the detection of breast cancer.

\begin{tabular}{|c|c|c|c|}
\hline Name of biomarker & Technology used for discovery & Type & Reference \\
\hline RS/DJ-1 & Humoral response & autoantibody & {$[36]$} \\
\hline p53 & Humoral response & autoantibody & [44-47] \\
\hline HSP60 & Humoral response & autoantibody & {$[48,49]$} \\
\hline HSP90 & Humoral response & autoantibody & {$[50,51]$} \\
\hline Mucin-related & Humoral response & autoantibody & {$[49,52-54]$} \\
\hline CA $15-3$ & Serum profiling & serum protein & {$[55,56]$} \\
\hline RS/DJ-1 & Serum profiling & serum protein & [36] \\
\hline HER-2/neu & Serum profiling & serum protein & {$[72]$} \\
\hline$\alpha$-2-HS-glycoprotein & Nipple aspirate fluid profiling & Ductal protein & {$[90]$} \\
\hline Lipophilin B & Nipple aspirate fluid profiling & Ductal protein & {$[90]$} \\
\hline beta-globin & Nipple aspirate fluid profiling & Ductal protein & {$[90]$} \\
\hline Hemopexin & Nipple aspirate fluid profiling & Ductal protein & {$[90]$} \\
\hline Vitamin D-binding protein & Nipple Aspirate Fluid Profiling & Ductal protein & {$[90]$} \\
\hline
\end{tabular}

autoantibodies has been associated with a reduced risk for disease progression in patients with breast cancer $[53,54]$. While the antigenic epitope on MUC1 (or, for that matter, any of the other breast tumor antigens discussed above) is unknown, MUC1 has been shown to be aberrantly glycosylated frequently in breast cancer [54]. At present, CA 153 (a soluble or secreted form of MUC1) has utility as a circulating marker for breast cancer $[55,56]$. Serial measurements of CA 15-3 have utility to detect recurrences and to monitor the treatment of metastatic breast cancer [55-57]. Additionally, the CA 15-3 concentration at initial presentation does have prognostic significance [58-62].

In order to circumvent many of the difficulties associated with 2D-PAGE (namely, inadequate resolution, slow throughput, and limited dynamic range), protein microarrays were developed that have the capability to screen patient's sera for autoantibodies directed against tumor antigens [63-66]. In comparison to traditional ELISAs that use single purified recombinant proteins, the protein microarrays are capable of presenting and analyzing $>1000$ tumor antigens simultaneously. In addition, as these tumor antigens are typically derived from diseased tissues or disease-related cells, they possess disease-related, potentially antigenic, posttranslational modifications not normally expressed by the particular cells or tissue. In this technology, proteins from diseased tissues or disease-related cell lines are separated by 2-dimensional liquid chromatography (chromatofocusing or ion exchange HPLC in the first dimension, followed by reverse phase HPLC in the second dimension). Following separation, all fractions ( $\geq 1700$ fractions) from each separation are printed onto nitrocellulose-coated microscope slides and are subsequently probed with sera from patients or control subjects [63-66]. As each reactive fraction may contain a number of different proteins, each reactive fraction would need to be further assessed to determine the tumor antigen of interest.

More recently, Ramachandran et al. [67, 68] developed a novel protein microarray technology, termed nucleic acid protein programmable array (NAPPA). NAPPA arrays are generated by printing full-length cDNA encoding the target proteins at each feature of the array. The proteins are then transcribed and translated by a cell-free system and immobilized in situ using epitope tags fused to the proteins. Although this technology circumvents many of the difficulties of traditional protein microarrays (i.e., the need to resolve complex protein lysates), the printed proteins on the array lack all normal posttranslational modifications. Thus, any antigenicity resulting from aberrant modification of tumor proteins is not assessed. Anderson and colleagues [69] utilized the NAPPA arrays to screen 4988 candidate tumor antigens with sera from patients with early stage breast cancer for autoantibodies. Twenty-eight of these antigens were confirmed using an independent serum cohort $(n=51$ cases $/ 38$ controls, $P<0.05)$. Using all 28 antigens, a classifier was identified with a sensitivity of $80.8 \%$ and a specificity of $61.6 \%$ $($ AUC $=0.756)$. Although the sensitivity and specificity are not high, these 28 recombinant protein antigens may be considered as potential biomarkers for the early detection of breast cancer.

It is not clear why only a subset of patients with a particular tumor type develop a humoral response to particular tumor antigens. Immunogenicity may depend on the level of expression, posttranslational modification, or other types of protein processing, the extent of which may be variable among tumors of a similar histological type. Other factors that may influence the immune response include variability among tumors and individuals in major histocompatibility complex molecules and in antigen presentation. Although a number of autoantibodies have been identified in breast cancer, in most cases, they occur in less than $50 \%$ of patient's sera. Therefore, they are not likely to be effective individually for the early detection of breast cancer but may show efficacy if utilized as a panel of biomarkers.

\section{Detection of Altered Plasma Protein Expression for Identification of Breast Cancer-Specific Biomarkers}

There has been great interest in the hypothesis that tumorspecific proteins may be found in patient's circulation, and 
they may have utility for the early detection of cancer. For example, proteins such as CA125 in ovarian cancer and prostate-specific antigen (PSA) in prostate cancer have been used clinically as diagnostic markers of cancer. CA125 is a mucin commonly employed as a diagnostic marker for epithelial ovarian cancer. PSA is secreted primarily by prostate epithelial cells into the seminal plasma and is one of the best characterized examples of a secreted glycoprotein used in cancer diagnostics.

There are a number of reports that have described aberrantly expressed proteins in the serum of breast cancer patients. The most widely used serum marker in breast cancer diagnostics is CA 15-3, which detects soluble forms of the mucin MUC1. MUC1 is normally found in the apical membrane of normal secretory epithelium. Following malignant transformation, however, MUC1 may be localized throughout the external surface of the entire plasma membrane. In addition, changes in MUC1 glycosylation have been reported during neoplastic transformation $[70,71]$. Although MUC1 is expressed in normal and neoplastic breast epithelium, the clinical utility of MUC1 measurements is confined to measurements of shed or soluble forms (termed CA 15-3), released from the cell surface by proteolytic cleavage. Unfortunately, CA 15-3 is not suitable for early detection, as serum levels are rarely increased in patients with early or localized breast cancer. The main utility for CA 15-3 is for monitoring therapy in patients with metastatic breast cancer.

Le Naour and coworkers [36] have evaluated RS/DJ-1 as a serum biomarker of breast cancer. In normal tissue, expression of RS/DJ-1 was observed in epithelium, smooth muscle, blood vessels, and nerves. All 15 (100\%) invasive ductal carcinomas and $3(100 \%)$ invasive lobular carcinomas showed some level of cytoplasmic and nuclear reactivity in the neoplastic cells. Significantly elevated levels of serum RS/DJ-1 was observed in the sera of $11 / 30$ patients with newly diagnosed breast cancer, as compared to serum from 25 healthy subjects. However, these authors did not evaluate serum RS/DJ-1 levels in patients with other types of breast lesions. Thus, it is unknown whether the increased serum RS/DJ-1 levels are cancer-specific.

In another study [72], significantly higher serum HER$2 /$ neu levels were found in patients with tissue overexpression of HER-2/neu. Univariate analysis showed that HER-2/neu serum levels were prognostic factors in disease-free survival and overall survival only in patients with tissue overexpression. When only patients with HER-2/neu overexpression in tissue were studied, tumor size, nodal involvement, and tumor markers (at least one positive) were found to be independent prognostic factors for both disease-free survival and overall survival.

\section{Use of Mass Spectrometric Methodologies for Identification of Breast Cancer-Specific Biomarkers}

Methodologies have been developed to directly analyze the proteins contained within complex protein mixtures, such as that found within human biofluids (plasma or serum, nipple aspirate fluid, ductal lavage fluid, saliva, etc.). Among these technologies, some, like SELDI (Surface-Enhanced Laser Desorption and Ionization) are mass spectrometry-based. A number of investigators have used SELDI-TOF mass spectrometry to interrogate serum [73-81] and nipple aspirate/ ductal lavage fluid [82-89] from patients with breast cancer. In one study, serum samples from women with or without breast cancer were analyzed using SELDI protein chip mass spectrometry [77]. Using a case-control study design, serum samples from 48 female patients with primary invasive breast cancer were compared with samples from 48 age- and sexmatched healthy controls. To increase the number of identifiable proteins, patient's serum was profiled on IMAC30 (activated with nickel) ProteinChip surfaces. Differences in protein intensity between breast cancer cases and controls were measured by the Mann-Whitney $U$ test and adjusted for confounding variables in a multivariate logistic regression model. Three peaks, with mass-to-charge ratio $(\mathrm{m} / \mathrm{z}) 4276$, 4292 and 8941 were found that showed significant decreased expression in cancer sera, as compared to control sera $(P<$ 0.001). One drawback of the SELDI technology, however, is that given the limited dynamic range of SELDI, it is likely that distinctive features observed in serum with this approach represent relatively abundant proteins that are not necessarily specific to breast cancer. Further, SELDI has difficulties in providing the identification of the distinctive proteins when used to directly profile complex protein mixtures.

\section{Mass-Spectrometric Profiling of Nipple Aspirate Fluid or Ductal Lavage Fluid}

Other mass spectrometric profiling methods have been utilized to profile proteins found in nipple aspirate fluid [90] and ductal lavage fluid in order to identify breast cancerspecific biomarkers. These investigators [90] analyzed paired nipple aspirate fluid samples from 18 women with stage I or stage II unilateral invasive breast cancer and 4 healthy volunteers using ICAT (isotope-coded affinity tag) labeling, followed by SDS-PAGE. Gel slices were cut from each sample, with subsequent analysis by liquid chromatography tandem mass spectrometry (LC-MS/MS). They identified 353 peptides from the tandem mass spectra. Alpha-2-HS-glycoprotein was found to be underexpressed in nipple aspirate fluid from tumor-bearing breasts, while lipophilin B, betaglobin, hemopexin and vitamin D-binding protein were all overexpressed. Unfortunately, these authors only identified abundant proteins whose over- or underexpression was somewhat modest. Moreover, these authors did not analyze nipple aspirate fluid from patients with inflammatory breast disease. Thus, conclusions cannot be drawn regarding breast cancerspecificity of protein expression.

\section{N-linked Glycan Profiling for Biomarker Identification in Breast Cancer Serum}

Glycoproteins are the most heterogeneous group of posttranslational modifications known in proteins. Glycans show a high structural diversity reflecting inherent functional 
diversity. $\mathrm{N}$ - and O-oligosaccharide variants on glycoproteins (glycoforms) can lead to alterations in protein activity or function that may manifest itself as overt disease $[91,92]$. Many clinical biomarkers and therapeutic targets in cancer are glycoproteins [93-95], such as CA125 in ovarian cancer, HER2/neu in breast cancer, and prostate-specific antigen (PSA) in prostate cancer. The human epidermal growth factor receptor 2 (HER2/neu) is a transmembrane glycoprotein, where the presence of HER2 overexpression appears to be a key factor in malignant transformation and is predictive of a poor prognosis in breast cancer. CA125 is a mucin commonly employed as a diagnostic marker for epithelial ovarian cancer. Although CA125 has been used as an ovarian cancer marker for a long time, many of its $\mathrm{O}$ - and $\mathrm{N}$-glycan structures have only recently been characterized [96]. PSA is secreted primarily by prostate epithelial cells into the seminal plasma. It is one of the best characterized examples of a secreted glycoprotein used in cancer diagnostics, and its glycoforms have been described [97]. The alteration in protein glycosylation that occurs through varying the heterogeneity of glycosylation sites or changing glycan structure of proteins on the cell surface and in body fluids has been shown to correlate with the development or progression of cancer and other disease states [98]. It has been reported that the glycosylation of PSA secreted by the tumor prostate cell line LNCaP differs significantly from that of PSA from seminal plasma (normal control). These carbohydrate differences allow a distinction to be made between PSA from normal and tumor origins and provide a valuable biochemical tool for diagnosis of prostate cancer [99].

There is growing evidence that glycan structures on glycoproteins are modified in breast cancer [100-109]. Breast cancer-associated alterations have been demonstrated for fucosylation groups and for sialylations on the plasma protein $\alpha$-1-proteinase inhibitor [106]. Increased GlcNAc $\beta 1$ 6 Man $\alpha 1$-6Man $\beta$-branching in asparagine-linked oligosaccharides has been observed in human tumor cells. The levels of the $\beta 1-6$ branched oligosaccharides were evaluated in a series of benign and malignant human breast biopsies. Normal human breast tissue and benign lesions showed low expression but $50 \%$ of the primary malignancies examined showed significantly elevated $\beta 1-6$ branching [107]. Subsequently, L-PHA (a lectin that binds specifically to the $\beta 1-6$ branched oligosaccharides) lectin histochemistry was performed on paraffin sections of human breast tissues. All breast carcinomas and epithelial hyperplasia with atypia demonstrated significantly increased L-PHA staining as compared to fibroadenomas and hyperplasia without atypia [108]. More recently, L-PHA reactive glycoproteins were identified from matched normal (nondiseased) and malignant tissue isolated from patients with invasive ductal breast carcinoma [109]. Comparison analysis of the data identified 34 proteins that were enriched by L-PHA fractionation in tumor relative to normal tissue for at least 2 cases of ductal invasive breast carcinoma. Of these 34 L-PHA tumor enriched proteins, 12 were common to all 4 matched cases analyzed.

Abd Hamid and coworkers [110] analyzed fluorescently tagged serum $N$-glycans of advanced breast cancer patients using exoglycosidases and LC-MS/MS. They found that the expression of a trisialylated triantennary glycan containing an $\alpha$-1,3-linked fucose was increased in the presence of breast cancer. Kyselova and coworkers. profiled the permethylated $\mathrm{N}$-glycans in sera of breast cancer patients at different stages (stages I to IV) using MALDI TOF/TOF MS in one study [111]. In a second study, they profiled reduced and methylated serum $\mathrm{N}$-glycans of late-stage breast cancer patients using nanoliquid chromatography (LC) chip/timeof-flight (TOF) MS [112]. In both studies, they found an increase in fucosylation in both core and branched segments of $\mathrm{N}$-glycans in the presence of breast cancer. In the latter study, they found a decrease in expression of a biantennarymonosialylated $\mathrm{N}$-linked glycan and an increase in expression of a fucosylated triantennary-trisialylated $N$-linked glycan in the presence of Stage IV breast cancer. These glycosylation changes in a tumor-secreted protein may reflect fundamental activity changes in the enzymes involved in the glycosylation pathway, either through altered levels of enzymes or altered enzymatic activity. Importantly, the changes in glycan structure may serve as early detection biomarkers of breast cancer.

\section{Summary}

Early detection of breast cancer, so as to diagnose and treat cancer in its preinvasive state prior to metastasis, may greatly impact the treatment and prognosis of patients with this common, but deadly, malignancy. Unfortunately, at present, suitable biomarkers have not been identified for the early detection of breast cancer. Biomarker discovery for this disease is still very much in its discovery phase. Multiple approaches have been developed, as described above, that hold promise for the identification of serum biomarkers. The protein biomarkers that have been identified to date do not possess the requisite sensitivity/specificity to have utility individually as a biomarker for the early detection of breast cancer but ultimately may have utility within a panel of protein biomarkers. Additionally, other emerging technologies, such as genetically engineered mouse models of breast cancer may have utility to identify panels of serum biomarkers that can be further explored in human sera. In order to determine the utility of any promising protein biomarkers, the candidates will need to be tested and validated by multiple independent studies using an adequately sized test and training set of sera samples from very early-stage breast cancer. Development of such resources, including serum from patients with nonmalignant breast lesions and prospective serum collection from individuals at high risk of being diagnosed with breast cancer as well as serum from patients with other breast lesions and other types (nonbreast) of malignancies is of critical need for the identification of biomarkers with utility for the early detection of breast cancer. Up until now, serum/plasma collection has been primarily performed in individual laboratories, using heterogeneous sample collection methods. The Human Proteome Organization (HUPO) has conducted a study to assess efficacious serum collection methods. These findings have 
lead to efforts presently being made by the National Cancer Institute, through the Early Detection Research Network, to develop suitable serum resources for both the discovery phase and the subsequent validation phase of biomarkers for the early detection of cancer. With the ultimate development of these standardized resources, it is expected that suitable biomarkers would be validated and have utility for the early clinical detection of breast cancer within the next five-to-ten years.

\section{Acknowledgment}

This work was supported by Award no. W81XWH-09-1-0043 from the DoD (Army). The information presented reflects the opinions of the authors only and does not reflect the opinion of the DoD.

\section{References}

[1] A. Jemal, R. Siegel, J. Xu, and E. Ward, "Cancer statistics, 2010," CA Cancer Journal for Clinicians, vol. 60, no. 5, pp. 277-300, 2010.

[2] Early Breast Cancer Trialists' Collaborative Group (EBCTCG), "Effects of chemotherapy and hormonal therapy for early breast cancer on recurrence and 15-year survival: an overview of the randomised trials," The Lancet, vol. 365, pp. 1687-1717, 2005.

[3] J. M. Nabholtz, A. Buzdar, M. Pollak et al., "Anastrozole is superior to tamoxifen as first-line therapy for advanced breast cancer in postmenopausal women: results of a North American multicenter randomized trial," Journal of Clinical Oncology, vol. 18, no. 22, pp. 3758-3767, 2000.

[4] J. Bonneterre, B. Thurlimann, J. F. Robertson et al., "Anastrozole versus tamoxifen as first-line therapy for advanced breast cancer in 668 postmenopausal women: results of the tamoxifen or arimidex randomized group efficacy and tolerability study," Journal of Clinical Oncology, vol. 18, no. 22, pp. 3748-3757, 2000.

[5] J. Bonneterre, A. Buzdar, J. M. Nabholtz et al., "Anastrozole is superior to tamoxifen as first-line therapy in hormone receptor positive advanced breast carcinoma," Cancer, vol. 92, no. 9, pp. 2247-2258, 2001.

[6] C. A. Hudis, "Trastuzumab-Mechanism of action and use in clinical practice," New England Journal of Medicine, vol. 357, no. 1, pp. 39-51, 2007.

[7] D. Bilancia, G. Rosati, A. Dinota, D. Germano, R. Romano, and L. Manzione, "Lapatinib in breast cancer" Annals of Oncology, vol. 18, supplement 6, pp. vi26-vi30, 2007.

[8] G. M. Higa and J. Abraham, "Lapatinib in the treatment of breast cancer," Expert Review of Anticancer Therapy, vol. 7, no. 9, pp. 1183-1192, 2007.

[9] R. W. Carlson, B. O. Anderson, H. J. Burstein et al., "Invasive breast cancer: clinical practice guidelines in oncology," Journal of the National Comprehensive Cancer Network, vol. 5, no. 3, pp. 246-312, 2007.

[10] B. J. Yoder, E. J. Wilkinson, and N. A. Massoll, "Molecular and morphologic distinctions between infiltrating ductal and lobular carcinoma of the breast," Breast Journal, vol. 13, no. 2, pp. 172-179, 2007.

[11] F. A. Tavassoli, "Invasive lobular carcinoma," in Pathology of the Breast, F. A. Tavassoli, Ed., pp. 426-36, Appleton \& Lange, Stamford, Conn, USA, 2nd edition, 1999.
[12] "Invasive lobular carcinoma," in Rosen's Breast Pathology, P. P. Rosen, Ed., pp. 627-52, Lippincott Williams \& Wilkins, Philadelphia, Pa, USA, 2nd edition, 2001.

[13] J. S. Reis-Filho, P. T. Simpson, T. Gale, and S. R. Lakhani, "The molecular genetics of breast cancer: the contribution of comparative genomic hybridization," Pathology Research and Practice, vol. 201, no. 11, pp. 713-725, 2005.

[14] S. E. Shackney and J. F. Silverman, "Molecular evolutionary patterns in breast cancer," Advances in Anatomic Pathology, vol. 10, no. 5, pp. 278-290, 2003.

[15] P. T. Simpson, J. S. Reis-Filho, T. Gale, and S. R. Lakhani, "Molecular evolution of breat cancer," Journal of Pathology, vol. 205, no. 2, pp. 248-254, 2005.

[16] D. E. Stange, B. Radlwimmer, F. Schubert et al., "Highresolution genomic profiling reveals association of chromosomal aberrations on $1 \mathrm{q}$ and $16 \mathrm{p}$ with histologic and genetic subgroups of invasive breast cancer," Clinical Cancer Research, vol. 12, no. 2, pp. 345-352, 2006.

[17] D. G. Albertson, C. Collins, F. McCormick, and J. W. Gray, "Chromosome aberrations in solid tumors," Nature Genetics, vol. 34, no. 4, pp. 369-376, 2003.

[18] D. G. Albertson and D. Pinkel, "Genomic microarrays in human genetic disease and cancer," Human Molecular Genetics, vol. 12, no. 2, pp. R145-R152, 2003.

[19] H. Buerger, E. C. Mommers, R. Littmann et al., "Ductal invasive G2 and G3 carcinomas of the breast are the end stages of at least two different lines of genetic evolution," Journal of Pathology, vol. 194, no. 2, pp. 165-170, 2001.

[20] H. Tsuda and S. Hirohashi, "Multiple developmental pathways of highly aggressive breast cancers disclosed by comparison of histological grades and c-erbB-2 expression patterns in both the non-invasive and invasive portions," Pathology International, vol. 48, no. 7, pp. 518-525, 1998.

[21] J. E. Somerville, L. A. Clarke, and J. D. Biggart, "c-erbB-2 overexpression and histological type of in situ and invasive breast carcinoma," Journal of Clinical Pathology, vol. 45, no. 1, pp. 16-20, 1992.

[22] A. N. Jain, K. Chin, A. L. Børresen-Dale et al., "Quantitative analysis of chromosomal CGH in human breast tumors associates copy number abnormalities with p53 status and patient survival," Proceedings of the National Academy of Sciences of the United States of America, vol. 98, no. 14, pp. 7952-7957, 2001.

[23] D. N. Poller, C. E. Hutchings, M. Galea et al., "p53 protein expression in human breast carcinoma: relationship to expression of epidermal growth factor receptor, c-erbB2 protein overexpression, and oestrogen receptor," British Journal of Cancer, vol. 66, no. 3, pp. 583-588, 1992.

[24] M. Barbareschi, E. Leonardi, F. A. Mauri, G. Serio, and P. Dalla Palma, "p53 and c-erbB-2 protein expression in breast carcinomas: an immunohistochemical study including correlations with receptor status, proliferation markers, and clinical stage in human breast cancer," American Journal of Clinical Pathology, vol. 98, no. 4, pp. 408-418, 1992.

[25] M. Rudas, R. Neumayer, M. F. X. Gnant, M. Mittelböck, R. Jakesz, and A. Reiner, "p53 Protein expression, cell proliferation and steroid hormone receptors in ductal and lobular in situ carcinomas of the breast," European Journal of Cancer A, vol. 33, no. 1, pp. 39-44, 1997.

[26] J. E. Eyfjord, S. Thorlacius, M. Steinarsdottir, R. Valgardsdottir, H. M. Ogmundsdottir, and K. Anamthawat-Jonsson, "p53 Abnormalities and genomic instability in primary human breast carcinomas," Cancer Research, vol. 55, no. 3, pp. 646651, 1995. 
[27] C. Wiltschke, I. Kindas-Muegge, A. Steininger, A. Reiner, G. Reinger, and P. N. Preis, "Coexpression of HER-2/neu and p53 is associated with a shorter disease-free survival in nodepositive breast cancer patients," Journal of Cancer Research and Clinical Oncology, vol. 120, no. 12, pp. 737-742, 1994.

[28] R. Seshadri, A. S. Y. Leong, K. Mccaul, F. A. Firgaira, V. Setlur, and D. J. Horsfall, "Relationship between p53 gene abnormalities and other tumour characteristics in breastcancer prognosis," International Journal of Cancer, vol. 69, no. 2, pp. 135-141, 1996.

[29] A. Goldhirsch, M. Colleoni, G. Domenighetti, and R. D. Gelber, "Systemic treatments for women with breast cancer: outcome with relation to screening for the disease," Annals of Oncology, vol. 14, no. 8, pp. 1212-1214, 2003.

[30] D. Lieberman, "How to screen for colon cancer," Annual Review of Medicine, vol. 49, pp. 163-172, 1998.

[31] J. A. Ferguson, "Early detection of unsuspected colon cancers in asymptomatic people," Diseases of the Colon and Rectum, vol. 36, no. 4, p. 411, 1993.

[32] J. S. Mandel, J. H. Bond, T. R. Church et al., "Reducing mortality from colorectal cancer by screening for fecal occult blood. Minnesota Colon Cancer Control Study," New England Journal of Medicine, vol. 328, no. 19, pp. 1365-1371, 1993.

[33] W. J. Catalona, "Management of cancer of the prostate," New England Journal of Medicine, vol. 331, no. 15, pp. 996-1004, 1995.

[34] S. J. Jacobsen, S. K. Katusic, E. J. Bergstralh et al., "Incidence of prostate cancer diagnosis in the eras before and after serum prostate-specific antigen testing," Journal of the American Medical Association, vol. 274, no. 18, pp. 1445-1449, 1995.

[35] E. Lynge, "Screening for cancer of the cervix uteri," World Journal of Surgery, vol. 13, no. 1, pp. 71-78, 1989.

[36] F. Le Naour, D. E. Misek, M. C. Krause et al., "Proteomicsbased identification of RS/DJ-1 as a novel circulating tumor antigen in breast cancer," Clinical Cancer Research, vol. 7, no. 11, pp. 3328-3335, 2001.

[37] F. M. Brichory, D. E. Misek, A. M. Yim et al., "An immune response manifested by the common occurrence of annexins I and II autoantibodies and high circulating levels of IL-6 in lung cancer," Proceedings of the National Academy of Sciences of the United States of America, vol. 98, no. 17, pp. 9824-9829, 2001.

[38] A. O. Güre, N. K. Altorki, E. Stockert, M. J. Scanlan, L. J. Old, and Y. T. Chen, "Human lung cancer antigens recognized by autologous antibodies: definition of a novel cDNA derived from the tumor suppressor gene locus on chromosome 3p21.3," Cancer Research, vol. 58, no. 5, pp. 1034-1041, 1998.

[39] E. Stockert, E. Jäger, Y. T. Chen et al., "A survey of the humoral immune response of cancer patients to a panel of human tumor antigens," Journal of Experimental Medicine, vol. 187, no. 8, pp. 1349-1354, 1998.

[40] K. Ben-Mahrez, I. Sorokine, D. Thierry et al., "Circulating antibodies against c-myc oncogene product in sera of colorectal cancer patients," International Journal of Cancer, vol. 46, no. 1, pp. 35-38, 1990.

[41] S. M. Pupa, S. Menard, S. Andreola, and M. I. Colnaghi, "Antibody response against the c-erbB-2 oncoprotein in breast carcinoma patients," Cancer Research, vol. 53, no. 24, pp. 5864-5866, 1993.

[42] S. F. Winter, J. D. Minna, B. E. Johnson, T. Takahashi, A. F. Gazdar, and D. P. Carbone, "Development of antibodies against p53 in lung cancer patients appears to be dependent on the type of p53 mutation," Cancer Research, vol. 52, no. 15, pp. 4168-4174, 1992.

[43] J. Raedle, G. Oremek, M. Welker, W. K. Roth, W. F. Caspary, and S. Zeuzem, "p53 autoantibodies in patients with pancreatitis and pancreatic carcinoma," Pancreas, vol. 13, no. 3, pp. 241-246, 1996.

[44] P. Lenner, F. Wiklund, S. O. Emdin et al., "Serum antibodies against p53 in relation to cancer risk and prognosis in breast cancer: a population-based epidemiological study," British Journal of Cancer, vol. 79, no. 5-6, pp. 927-932, 1999.

[45] T. Soussi, "p53 Antibodies in the sera of patients with various types of cancer: a review," Cancer Research, vol. 60, no. 7, pp. 1777-1788, 2000.

[46] K. Angelopoulou, H. Yu, B. Bharaj, M. Giai, and E. P. Diamandis, "p53 Gene mutation, tumor p53 protein overexpression, and serum $\mathrm{p} 53$ autoantibody generation in patients with breast cancer," Clinical Biochemistry, vol. 33, no. 1, pp. 53-62, 2000.

[47] A. Kulić, M. Sirotković-Skerlev, S. Jelisavac-Ćosić, D. Herceg, Z. Kovač, and D. Vrbanec, "Anti-p53 antibodies in serum: relationship to tumor biology and prognosis of breast cancer patients," Medical Oncology, vol. 27, no. 3, pp. 887-893, 2010.

[48] C. Desmetz, F. Bibeau, F. Boissière et al., "Proteomics-based identification of HSP60 as a tumor-associated antigen in early stage breast cancer and ductal carcinoma in situ," Journal of Proteome Research, vol. 7, no. 9, pp. 3830-3837, 2008.

[49] C. Desmetz, C. Bascoul-Mollevi, P. Rochaix et al., "Identification of a new panel of serum autoantibodies associated with the presence of in situ carcinoma of the breast in younger women," Clinical Cancer Research, vol. 15, no. 14, pp. 47334741, 2009.

[50] S. E. Conroy, S. L. Gibson, G. Brunstrom, D. Isenberg, Y. Luqmani, and D. S. Latchman, "Autoantibodies to $90 \mathrm{kD}$ heat-shock protein in sera of breast cancer patients," The Lancet, vol. 345, no. 8942, p. 126, 1995.

[51] S. E. Conroy, P. D. Sasieni, I. Fentiman, and D. S. Latchman, "Autoantibodies to the $90 \mathrm{kDa}$ heat shock protein and poor survival in breast cancer patients," European Journal of Cancer, vol. 34, no. 6, pp. 942-943, 1998.

[52] S. Von Mensdorff-Pouilly, M. M. Gourevitch, P. Kenemans et al., "Humoral immune response to polymorphic epithelial mucin (MUC-1) in patients with benign and malignant breast tumours," European Journal of Cancer A, vol. 32, no. 8, pp. 1325-1331, 1996.

[53] S. Von Mensdorff-Pouilly, A. A. Verstraeten, P. Kenemans et al., "Survival in early breast cancer patients is favorably influenced by a natural humoral immune response to polymorphic epithelial mucin," Journal of Clinical Oncology, vol. 18 , no. 3, pp. 574-583, 2000.

[54] O. Blixt, D. Bueti, B. Burford et al., "Autoantibodies to aberrantly glycosylated MUC1 in early stage breast cancer are associated with a better prognosis," Breast Cancer Research, vol. 13, no. 2, article R25, 2011.

[55] M. J. Duffy, "CA 15-3 and related mucins as circulating markers in breast cancer," Annals of Clinical Biochemistry, vol. 36, no. 5, pp. 579-586, 1999.

[56] M. J. Duffy, D. Evoy, and E. W. McDermott, "CA 15-3: uses and limitation as a biomarker for breast cancer," Clinica Chimica Acta, vol. 411, no. 23-24, pp. 1869-1874, 2010.

[57] B. De La Lande, K. Hacene, J. L. Floiras, N. Alatrakchi, and M. F. Pichon, "Prognostic value of CA 15.3 kinetics for metastatic breast cancer," International Journal of Biological Markers, vol. 17, no. 4, pp. 231-238, 2002. 
[58] F. G. Ebeling, P. Stieber, M. Untch et al., "Serum CEA and CA 15-3 as prognostic factors in primary breast cancer," British Journal of Cancer, vol. 86, no. 8, pp. 1217-1222, 2002.

[59] M. Gion, P. Boracchi, R. Dittadi et al., "Prognostic role of serum CA15.3 in 362 node-negative breast cancers. An old player for a new game," European Journal of Cancer, vol. 38, no. 9, pp. 1181-1188, 2002.

[60] E. J. Kumpulainen, R. J. Keskikuru, and R. T. Johansson, "Serum tumor marker CA 15.3 and stage are the two most powerful predictors of survival in primary breast cancer," Breast Cancer Research and Treatment, vol. 76, no. 2, pp. 95102, 2002.

[61] A. Martín, M. D. Corte, A. M. Álvarez et al., "Prognostic value of pre-operative serum CA 15.3 levels in breast cancer," Anticancer Research, vol. 26, no. 5B, pp. 3965-3971, 2006.

[62] R. Molina, X. Filella, J. Alicarte et al., "Prospective evaluation of CEA and CA 15.3 in Patients with locoregional breast cancer," Anticancer Research, vol. 23, no. 2A, pp. 1035-1041, 2003.

[63] J. Madoz-Gúrpide, H. Wang, D. E. Misek, F. Brichory, and S. M. Hanash, "Protein based microarrays: a tool for probing the proteome of cancer cells and tissues," Proteomics, vol. 1, no. 10, pp. 1279-1287, 2001.

[64] M. J. Nam, J. Madoz-Gurpide, H. Wang et al., "Molecular profiling of the immune response in colon cancer using protein microarrays: occurrence of autoantibodies to ubiquitin C-terminal hydrolase L3," Proteomics, vol. 3, no. 11, pp. 2108-2115, 2003.

[65] K. Bouwman, J. Qiu, H. Zhou et al., "Microarrays of tumor cell derived proteins uncover a distinct pattern of prostate cancer serum immunoreactivity," Proteomics, vol. 3, no. 11, pp. 2200-2207, 2003.

[66] J. Qiu, J. Madoz-Gurpide, D. E. Misek et al., "Development of natural protein microarrays for diagnosing cancer based on an antibody response to tumor antigens," Journal of Proteome Research, vol. 3, no. 2, pp. 261-267, 2004.

[67] N. Ramachandran, E. Hainsworth, B. Bhullar et al., "Selfassembling protein microarrays," Science, vol. 305 , no. 5680, pp. 86-90, 2004.

[68] N. Ramachandran, J. V. Raphael, E. Hainsworth et al., "Nextgeneration high-density self-assembling functional protein arrays," Nature Methods, vol. 5, no. 6, pp. 535-538, 2008.

[69] K. S. Anderson, S. Sibani, G. Wallstrom et al., "Protein microarray signature of autoantibody biomarkers for the early detection of breast cancer," Journal of Proteome Research, vol. 10, no. 1, pp. 85-96, 2011.

[70] C. L. Hattrup and S. J. Gendler, "Structure and function of the cell surface (tethered) mucins," Annual Review of Physiology, vol. 70, pp. 431-457, 2008.

[71] D. W. Kufe, "Mucins in cancer: function, prognosis and therapy," Nature Reviews Cancer, vol. 9, no. 12, pp. 874-885, 2009.

[72] R. Molina, J. M. Augé, J. M. Escudero et al., "Evaluation of tumor markers (HER-2/neu oncoprotein, CEA, and CA 15.3) in patients with locoregional breast cancer: prognostic value," Tumor Biology, vol. 31, no. 3, pp. 171-180, 2010.

[73] Y. Fan, J. Wang, Y. Yang et al., "Detection and identification of potential biomarkers of breast cancer," Journal of Cancer Research and Clinical Oncology, vol. 136, no. 8, pp. 12431254, 2010.

[74] M. C. Gast, E. J. van Dulken, T. K. van Loenen et al., "Detection of breast cancer by surface-enhanced laser desorption/ionization time-of-flight mass spectrometry tissue and serum protein profiling," International Journal of Biological Markers, vol. 24, no. 3, pp. 130-141, 2009.

[75] M. C. Gast, C. H. van Gils, L. F. Wessels et al., "Serum protein profiling for diagnosis of breast cancer using SELDI-TOF MS," Oncology Reports, vol. 22, no. 1, pp. 205-213, 2009.

[76] A. Lebrecht, D. Boehm, M. Schmidt, H. Koelbl, and F. H. Grus, "Surface-enhanced laser desorption/ionisation timeof-flight mass spectrometry to detect breast cancer markers in tears and serum," Cancer Genomics and Proteomics, vol. 6, no. 2, pp. 75-84, 2009.

[77] A. W. Van Winden, M. C. W. Gast, J. H. Beijnen et al., "Validation of previously identified serum biomarkers for breast cancer with SELDI-TOF MS: a case control study," BMC Medical Genomics, vol. 2, article 4, 2009.

[78] C. Belluco, E. F. Petricoin, E. Mammano et al., "Serum proteomic analysis identifies a highly sensitive and specific discriminatory pattern in stage 1 breast cancer," Annals of Surgical Oncology, vol. 14, no. 9, pp. 2470-2476, 2007.

[79] G. Ricolleau, C. Charbonnel, L. Lodé et al., "Surfaceenhanced laser desorption/ionization time of flight mass spectrometry protein profiling identifies ubiquitin and ferritin light chain as prognostic biomarkers in node-negative breast cancer tumors," Proteomics, vol. 6, no. 6, pp. 19631975, 2006

[80] C. Laronga, S. Becker, P. Watson et al., "SELDI-TOF serum profiling for prognostic and diagnostic classification of breast cancers," Disease Markers, vol. 19, no. 4-5, pp. 229-238, 2003.

[81] J. Li, Z. Zhang, J. Rosenzweig, Y. Y. Wang, and D. W. Chan, "Proteomics and bioinformatics approaches for identification of serum biomarkers to detect breast cancer," Clinical Chemistry, vol. 48, no. 8, pp. 1296-1304, 2002.

[82] E. R. Sauter, W. Davis, W. Qin et al., "Identification of a $\beta$-casein-like peptide in breast nipple aspirate fluid that is associated with breast cancer," Biomarkers in Medicine, vol. 3, no. 5, pp. 577-588, 2009.

[83] J. Zhou, B. Trock, T. N. Tsangaris et al., "A unique proteolytic fragment of alpha1-antitrypsin is elevated in ductal fluid of breast cancer patient," Breast Cancer Research and Treatment, vol. 123, no. 1, pp. 73-86, 2010.

[84] J. L. Noble, R. S. Dua, G. R. Coulton, C. M. Isacke, and G. P. H. Gui, "A comparative proteinomic analysis of nipple aspiration fluid from healthy women and women with breast cancer," European Journal of Cancer, vol. 43, no. 16, pp. 23152320, 2007.

[85] J. He, J. Gornbein, D. Shen et al., "Detection of breast cancer biomarkers in nipple aspirate fluid by SELDI-TOF and their identification by combined liquid chromatography-tandem mass spectrometry," International Journal of Oncology, vol. 30, no. 1, pp. 145-154, 2007.

[86] J. Li, J. Zhao, X. Yu et al., "Identification of biomarkers for breast cancer in nipple aspiration and ductal lavage fluid," Clinical Cancer Research, vol. 11, no. 23, pp. 8312-8320, 2005.

[87] T. M. Pawlik, H. Fritsche, K. R. Coombes et al., "Significant differences in nipple aspirate fluid protein expression between healthy women and those with breast cancer demonstrated by time-of-flight mass spectrometry," Breast Cancer Research and Treatment, vol. 89, no. 2, pp. 149-157, 2005.

[88] E. R. Sauter, S. Shan, J. E. Hewett, P. Speckman, and G. C. $\mathrm{Du}$ Bois, "Proteomic analysis of nipple aspirate fluid using SELDl-TOF-MS," International Journal of Cancer, vol. 114, no. 5, pp. 791-796, 2005.

[89] C. P. Paweletz, B. Trock, M. Pennanen et al., "Proteomic patterns of nipple aspirate fluids obtained by SELDI-TOF: 
potential for new biomarkers to aid in the diagnosis of breast cancer," Disease Markers, vol. 17, no. 4, pp. 301-307, 2001.

[90] T. M. Pawlik, D. H. Hawke, Y. Liu et al., "Proteomic analysis of nipple aspirate fluid from women with early-stage breast cancer using isotope-coded affinity tags and tandem mass spectrometry reveals differential expression of vitamin D binding protein," BMC Cancer, vol. 6, article no. 68, 2006.

[91] P. M. Rudd, T. Elliott, P. Cresswell, I. A. Wilson, and R. A. Dwek, "Glycosylation and the immune system," Science, vol. 291, no. 5512, pp. 2370-2376, 2001.

[92] A. Kobata and J. Amano, "Altered glycosylation of proteins produced by malignant cells, and application for the diagnosis and immunotherapy of tumours," Immunology and Cell Biology, vol. 83, no. 4, pp. 429-439, 2005.

[93] D. H. Dube and C. R. Bertozzi, "Glycans in cancer and inflammation-Potential for therapeutics and diagnostics," Nature Reviews Drug Discovery, vol. 4, no. 6, pp. 477-488, 2005.

[94] T. F. Ørntoft and E. M. Vestergaard, "Clinical aspects of altered glycosylation of glycoproteins in cancer," Electrophoresis, vol. 20, no. 2, pp. 362-371, 1999.

[95] O. J. Semmes, G. Malik, and M. Ward, "Application of mass spectrometry to the discovery of biomarkers for detection of prostate cancer," Journal of Cellular Biochemistry, vol. 98, no. 3, pp. 496-503, 2006.

[96] N. K. Wong, R. L. Easton, M. Panico et al., "Characterization of the oligosaccharides associated with the human ovarian tumor marker CA125," Journal of Biological Chemistry, vol. 278, no. 31, pp. 28619-28634, 2003.

[97] S. Prakash and P. W. Robbins, "Glycotyping of prostate specific antigen," Glycobiology, vol. 10, no. 2, pp. 173-176, 2000.

[98] T. M. Block, M. A. Comunale, M. Lowman et al., "Use of targeted glycoproteomics to identify serum glycoproteins that correlate with liver cancer in woodchucks and humans," Proceedings of the National Academy of Sciences of the United States of America, vol. 102, no. 3, pp. 779-784, 2005.

[99] R. Peracaula, G. Tabarés, L. Royle et al., "Altered glycosylation pattern allows the distinction between prostate-specific antigen (PSA) from normal and tumor origins," Glycobiology, vol. 13, no. 6, pp. 457-470, 2003.

[100] D. F. Hayes, M. Abe, J. Siddiqui, C. Tondini, and D. W. Kufe, "Clinical and molecular investigations of the DF3 breast cancer-associated antigen," in Immunological Approaches to the Diagnosis and Therapy of Breast Cancer II, R. L. Ceriani, Ed., pp. 45-53, Plenum, New York, NY, USA, 1989.

[101] S. R. Hull, A. Bright, K. L. Carraway, M. Abe, D. F. Hayes, and D. W. Kufe, "Oligosaccharide differences in the DF3 sialomucin antigen from normal human milk and the BT-20 human breast carcinoma cell line," Cancer Communications, vol. 1, no. 4, pp. 261-267, 1989.

[102] L. Perey, D. F. Hayes, and D. Kufe, "Effects of differentiating agents on cell surface expression of the breast carcinomaassociated DF3-P epitope," Cancer Research, vol. 52, no. 22, pp. 6365-6370, 1992.

[103] L. Perey, D. F. Hayes, P. Maimonis, M. Abe, C. O'Hara, and D. W. Kufe, "Tumor selective reactivity of a monoclonal antibody prepared against a recombinant peptide derived from the DF3 human breast carcinoma-associated antigen," Cancer Research, vol. 52, no. 9, pp. 2563-2568, 1992.

[104] R. Sewell, M. Bäckström, M. Dalziel et al., "The ST6GalNAcI sialyltransferase localizes throughout the golgi and is responsible for the synthesis of the tumor-associated sialylTn O-glycan in human breast cancer," Journal of Biological Chemistry, vol. 281, no. 6, pp. 3586-3594, 2006.

[105] J. M. Burchell, A. Mungul, and J. Taylor-Papadimitriou, "O-linked glycosylation in the mammary gland: changes that occur during malignancy," Journal of Mammary Gland Biology and Neoplasia, vol. 6, no. 3, pp. 355-364, 2001.

[106] M. T. Goodarzi and G. A. Turner, "Decreased branching, increased fucosylation and changed sialylation of alpha-1proteinase inhibitor in breast and ovarian cancer," Clinica Chimica Acta, vol. 236, no. 2, pp. 161-171, 1995.

[107] J. W. Dennis and S. Laferte, "Oncodevelopmental expression of -GlcNAc $\beta 1-6 \mathrm{Man} \alpha 1-6 \mathrm{Man} \beta 1$ - branched asparaginelinked oligosaccharides in murine tissues and human breast carcinomas," Cancer Research, vol. 49, no. 4, pp. 945-950, 1989.

[108] B. Fernandes, U. Sagman, M. Auger, M. Demetrio, and J. W. Dennis, " $\beta 1-6$ branched oligosaccharides as a marker of tumor progression in human breast and colon neoplasia," Cancer Research, vol. 51, no. 2, pp. 718-723, 1991.

[109] K. L. Abbott, K. Aoki, J. M. Lim et al., "Targeted glycoproteomic identification of biomarkers for human breast carcinoma," Journal of Proteome Research, vol. 7, no. 4, pp. 1470-1480, 2008.

[110] U. M. Abd Hamid, L. Royle, R. Saldova et al., "A strategy to reveal potential glycan markers from serum glycoproteins associated with breast cancer progression," Glycobiology, vol. 18, no. 12, pp. 1105-1118, 2008.

[111] Z. Kyselova, Y. Mechref, P. Kang et al., "Breast cancer diagnosis and prognosis through quantitative measurements of serum glycan profiles," Clinical Chemistry, vol. 54, no. 7, pp. 1166-1175, 2008.

[112] W. R. Alley, M. Madera, Y. Mechref, and M. V. Novotny, "Chip-based reversed-phase liquid chromatography-mass spectrometry of permethylated $\mathrm{N}$-linked glycans: a potential methodology for cancer-biomarker discovery," Analytical Chemistry, vol. 82, no. 12, pp. 5095-5106, 2010. 

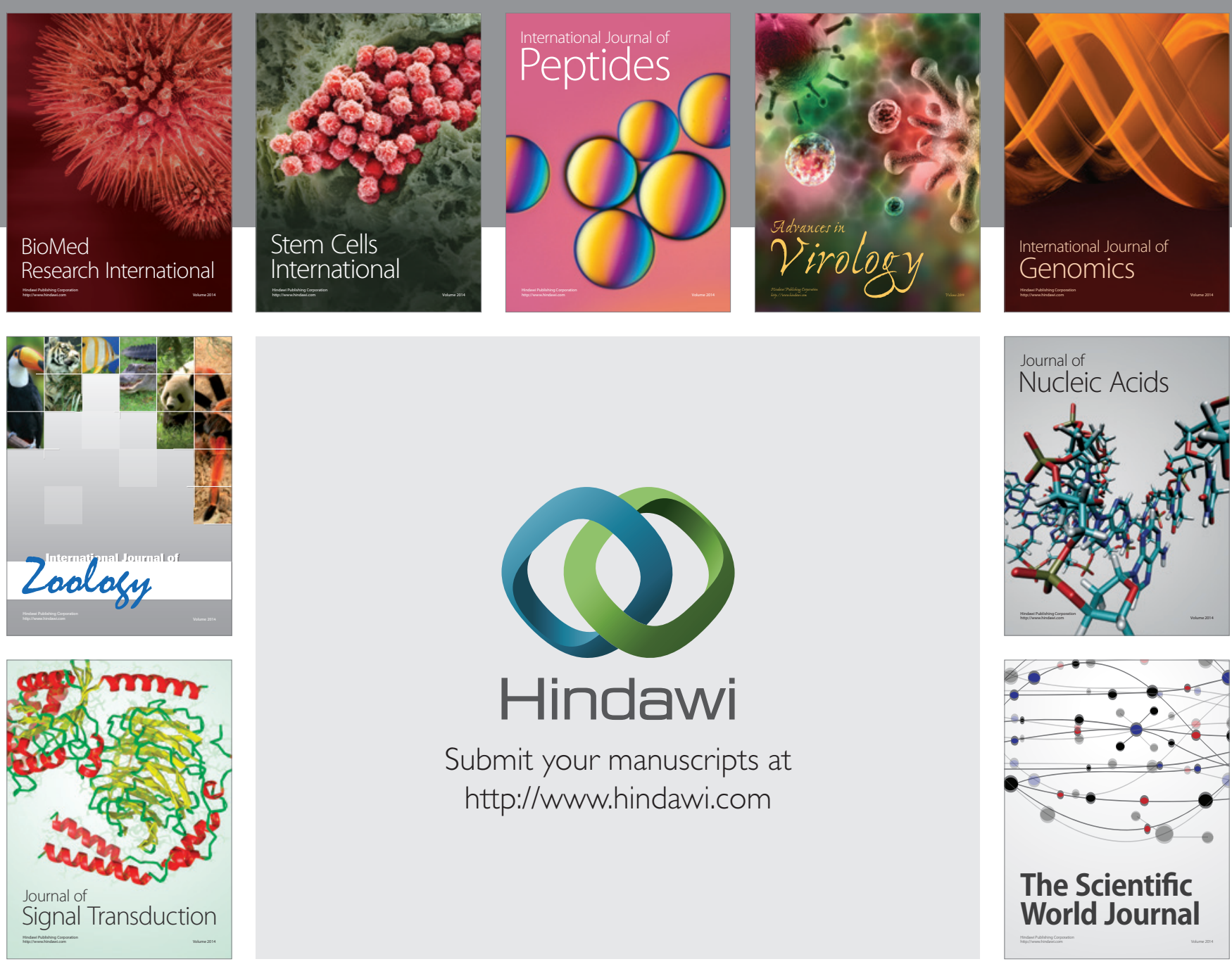

Submit your manuscripts at

http://www.hindawi.com
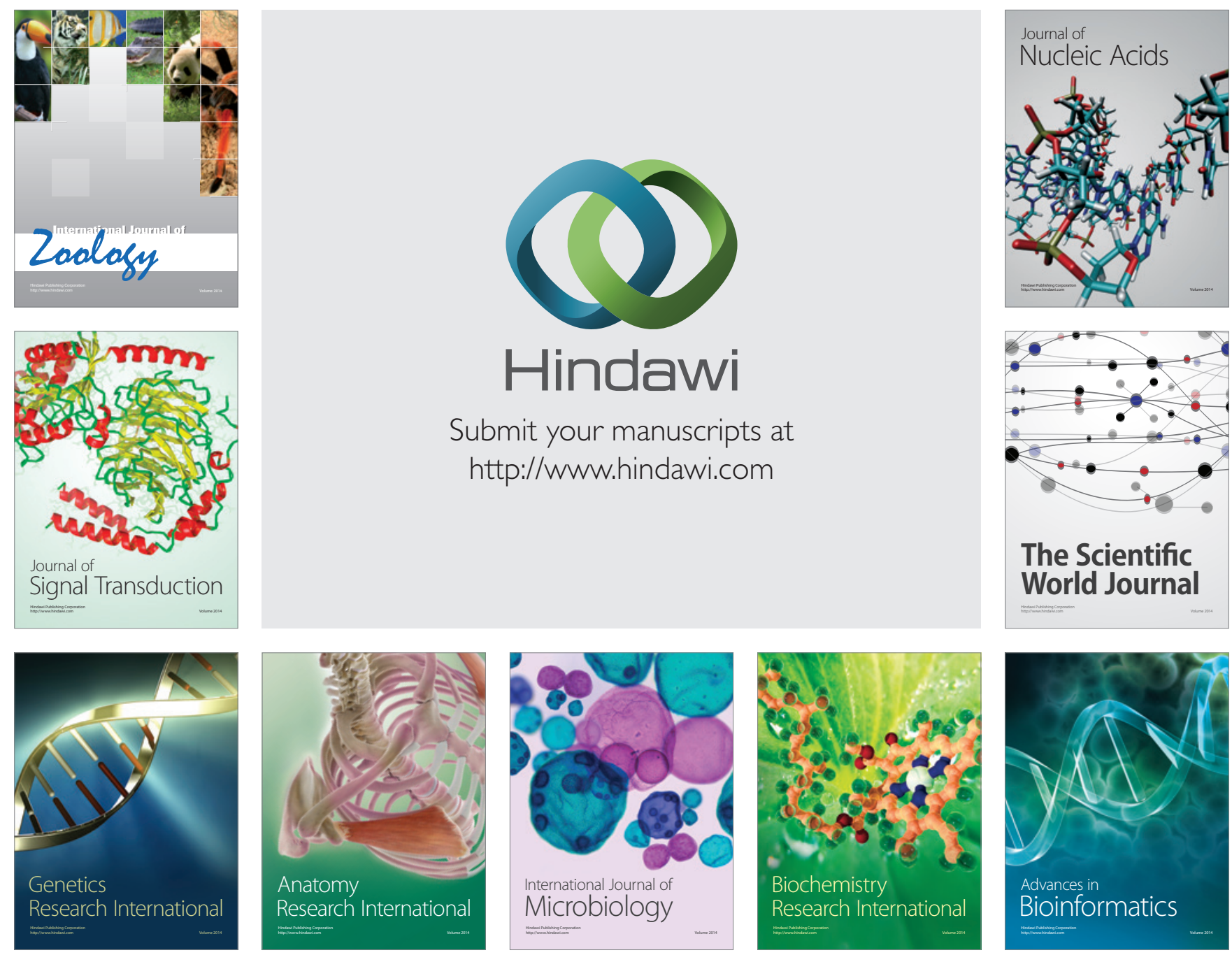

The Scientific World Journal
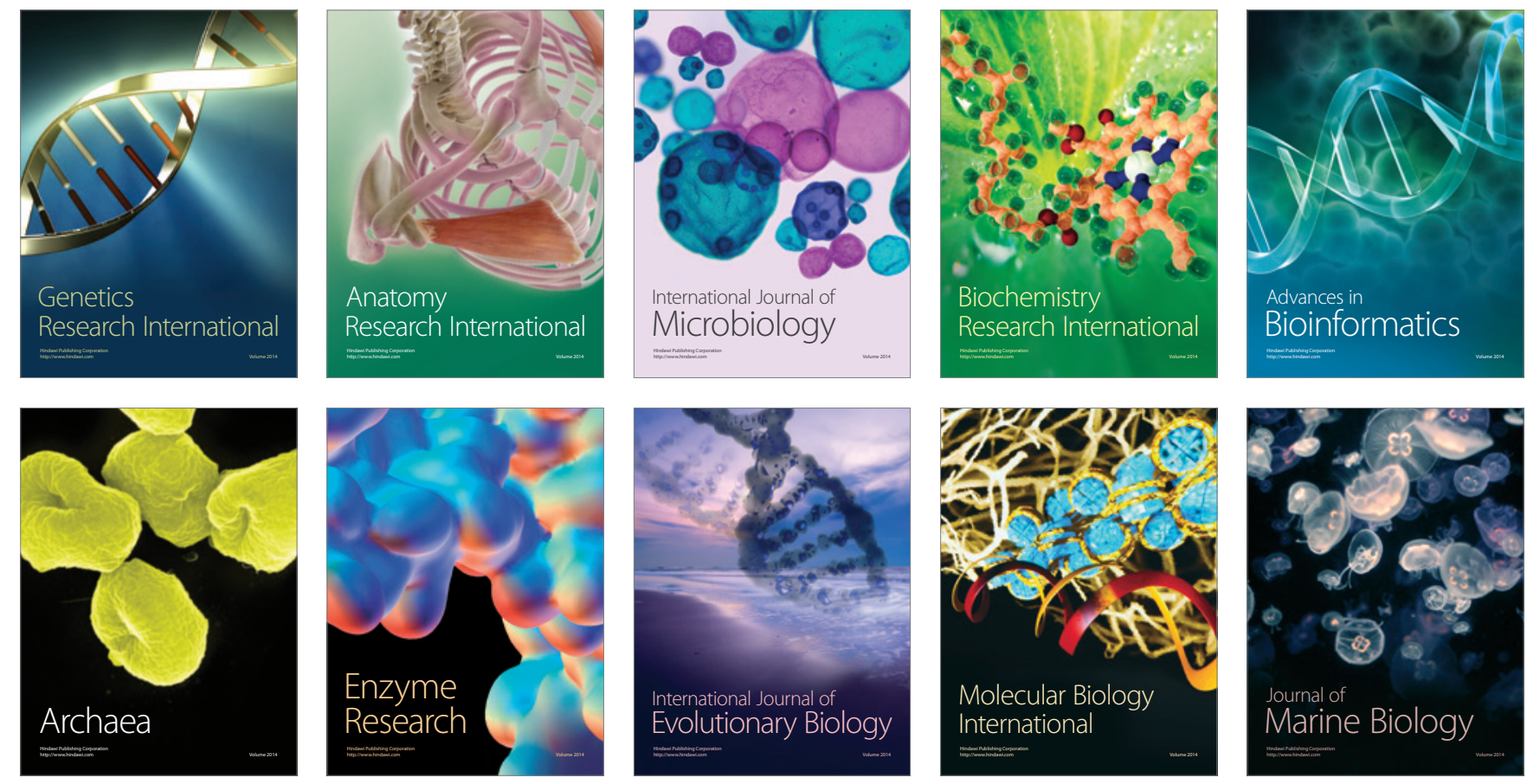